\title{
BUILDING BRIDGES: AN APPROACH TO THE INTEGRATION OF ENGLiSH LANGUAGE EduCATION IN FirST-YEAR APPLIED SCIENCE COURSES FOR INTERNATIONAL STUdENTS
}

\author{
Mike Murphy ${ }^{l}$ and Gabriel Potvin ${ }^{1,2}$ \\ ${ }^{1}$ Vantage College, University of British Columbia \\ ${ }^{2}$ Department of Chemical and Biological Engineering, University of British Columbia \\ mike.murphy@ubc.ca, gabriel.potvin@ubc.ca
}

\begin{abstract}
Vantage College at UBC offers innovative specialized first-year programs for international students that integrate core content courses with complementary language education to allow participants to hone their communication skills while meeting regular academic requirements. In the Applied Science stream of the Vantage program, each first-year engineering course is paired with a language enrichment course, and their respective instructors collaborate, tailoring their content and delivery to improve both the learning of technical material and the effective development of communication skills. This paper outlines the partnership between two physical chemistry courses and their linked language courses. Insights into the nature and logistics of this type of collaboration are presented, and the effectiveness of this training approach is evaluated in relation to the students' mastery of technical content and improvement of English communication skills. Specific challenges and future improvements of the program are also discussed.
\end{abstract}

Keywords: First-Year Education, International Students, Content Integration, Technical Communication

\section{INTRODUCTION}

Globalization and the rapidly increasing prosperity of key international markets continue to fuel a growing demand for North-American post-secondary education, and Canadian Engineering and Applied Science Faculties are not excluded from this trend. Although international students admitted to engineering programs in Canada are technically proficient, language and cultural barriers can sometimes prevent them from fully integrating into the academic and engineering communities and present obstacles to their success as they advance through their studies. Universities across North America have used a number of approaches and created a variety of academic models to attract and serve these international students, with varied degrees of success [1].

Vantage College (VC) at the University of British Columbia (UBC) was established to offer innovative interdisciplinary first-year programs to international students that integrate core content courses with language training and support programs that allow participants to hone their communication skills while meeting the academic requirements of their respective disciplines. These programs are offered exclusively to international students who have a strong foundation in English, but who do not quite meet the language proficiency requirements set forth by UBC for entry into its regular programs. Participants take all of their first year courses with their Vantage cohort, and, upon successful completion of the program, which requires passing all technical and language-focused courses with an overall average of $60 \%$, they join their "direct-entry" counterparts for the remainder of their undergraduate studies. VC first opened its doors for the 2014-2015 academic year, offering programs for students in the faculties of Science and Arts, and offered Management and Applied Science programs beginning in 2015-2016.

At UBC, students admitted to Applied Science (APSC) all complete a common first year before applying through a competitive process to their preferred specialized engineering discipline, which starts in second year. The APSC stream of the Vantage program works much the same way, with all Vantage students completing, over three terms (two standard academic terms and a condensed summer term), first-year core content courses that are equivalent to those taken by direct-entry students. Subsequently, these students apply for their preferred disciplines through the same competitive process as other, non-Vantage students. The difference between the two programs lies primarily in Vantage integrating language instruction throughout the technical curriculum to facilitate the transition of international students into the broader APSC academic community. 
In the APSC Vantage program, each core engineering course is linked with a language enrichment course, and their respective instructors collaborate closely. This paper serves as an introduction to the VC program and describes the partnership between two physical chemistry courses offered in the APSC stream and the language courses associated with them. The approach taken towards this type of collaboration is presented, examples of integrated learning activities are outlined, and the effectiveness of this training approach is evaluated in relation to the students' mastery of technical content and improvement of English communication skills. Although the collaboration described here was successful, as evidenced for example by the marked improvements in the quality of lab reports, both in terms of communication and depth of analysis, this was the pilot year for this program, and improvements to be implemented in the 2016-2017 year are also presented.

\section{INSTRUCTIONAL APPROACH}

The approach to core content and language education within the APSC Vantage program has the primary objectives of facilitating the transition of international students to an English language Canadian academic environment, while supporting their academic performance in technical engineering courses through the improvement of their communication skills. In particular, focus is placed on abilities related to understanding and participating in lectures, understanding and breaking down complex word problems, and analyzing and communicating technical data and results in lab reports and other deliverables required by engineering courses. The following outlines the instructional approach taken in the two engineering-language tandem courses and the nature of the collaboration between the instructors.

\subsection{Description of Linked Courses}

The two engineering courses in question are first-year physical chemistry courses taught by the same instructor over two consecutive semesters. They are composed of lectures, tutorials focusing on problem-solving and practical exercises, and lab sessions. These courses cover topics that include states of matter and material properties, energy, thermodynamics and heat transfer, chemical kinetics, solution chemistry, and electrochemistry, as well as introductory-level concepts in inorganic chemistry. These courses have equivalencies in the direct-entry program, and the academic expectations for all assignments, exams and lab reports are the same. The courses are taught at the same pace and level of difficulty as the direct-entry courses, albeit with a heightened sensitivity to students' language needs.
The language courses focus on the development of technical and general academic vocabulary, listening skills for lecture comprehension, technical writing (particularly as it relates to the different components of engineering laboratory reports), and oral communication strategies for the presentation of technical information, all in the context of the physical chemistry topic being covered at any given time. These language courses are designed to support students as they learn the technical material from the content courses, while raising their communication skills to a level that will allow them to succeed in the directentry program starting in second year. The assignments and exams in these language courses focus solely on language skills, but in a discipline-specific context, and are evaluated completely independently of the content courses. Students are required to successfully pass both content and language courses in order to complete the program and proceed to the second year of their studies.

\subsection{Language Instruction Pedagogy}

In operationalizing Vantage College's integrated language-content learning model, the college's Academic English Program (AEP) has drawn on the theoretical insights into language use provided by the school of linguistic theory known as Systemic Functional Linguistics (SFL), which aims to describe the relationship between language form and functional meaning, i.e. showing how the particular vocabulary and grammar choices that communicators make contribute to the achievement of given communicative functions [2]. For example, an SFL analysis of undergraduate engineering textbooks as compared to scholarly engineering research articles might point out that in the former, the authors often refer to themselves and to readers directly in order to create a friendly and unintimidating learning atmosphere whereas in the latter, the presence of both the author and the reader tend to be downplayed in order to project a sense of academic formality and scientific objectivity. For the Vantage AEP, SFL serves as a lens through which discipline-specific language for achieving discipline-specific communicative functions can be described and clarified to learners.

\subsection{Nature of the Collaboration}

The association of the core content and language courses takes a collaborative interdisciplinary approach. The language instructor attends all of the content course lectures to keep track of the course progression, gain a better understanding of the technical material presented, and identify areas in which students would benefit from additional communications training. This immersion in engineering and an understanding of the relevant concepts 
are crucial to the effective training of the students in writing lab reports or giving technical oral presentations that are related to these subjects. The language instructor can also provide valuable periodic feedback to the content instructor regarding the pacing of the lectures and student confidence with, and comprehension of, the lessons and concepts presented.

Similarly, the technical instructor attends all of the language lectures, and provides suggestions for activities or areas of focus based on assessed student progress and performance, supplies supporting technical material, and gives short technical presentations to supplement the language training activities. In addition, he ensures that the material and activities covered in the language lectures are relevant and support the technical content.

This type of collaboration has the added benefit of being a truly interdisciplinary undertaking, which leads to valuable discussions and provides insights into the teaching practices and learning outcomes of both disciplines from outside perspectives. The language instructor does not have an engineering background and is learning the technical content for the first time, and the content instructor likewise does not have formal language instruction training. The pedagogical exchanges that arise from this type of collaboration serve to enrich and improve both courses.

\section{ENGINEERING-RELEVANT LANGUAGE ACTIVITIES}

\subsection{Overview}

Over the two terms of the language course, several types of activities were employed with a view to achieving overall course objectives. These activities focused on helping students improve their language skills in relation to typical genres of undergraduate engineering discourse such as lectures, textbook readings, lab reports, and oral presentations of technical material. More specifically, students engaged in activities that focused on the following:

i. Developing the ability to acquire needed vocabulary, both general and technical, through the creation of a collaborative class wiki composed of information about unknown words extracted from assigned textbook readings. This involved an emphasis on developing good dictionary skills as well as an awareness of 'collocation' patterns.

ii. Improving lab report writing skills through tasks that encouraged students to focus on the language used to achieve particular communicative effects in this genre. iii. Simultaneously honing reading, speaking, and listening skills for engineering study by reading textbook excerpts or popular accounts of cuttingedge engineering research and having to summarize and explain key concepts to classmates in small group discussions or oral presentations to the class.

iv. Developing lecture listening skills by transcribing excerpts of one of the content course instructor's lectures and, as a class, analyzing the linguistic characteristics of this spoken 'text', especially as compared to written texts such as textbook readings.

v. Improving grammatical accuracy of writing by means of activities in which students received language-focused instructor feedback on a course topic summary or lab report they had written and then revising the language of the assignment for greater correctness and communicative effectiveness.

Two examples, namely the lab report writing tasks and a podcast listening activity, are further described in the following section to better illustrate the type of training provided to students participating in this program, and to provide examples of opportunities that exist for technical and language instructors to collaborate to improve the learning outcomes of both courses.

\subsection{Writing Laboratory Reports}

The first-term report writing tasks were assigned over a series of weekly language classes and took place in parallel with the students conducting experiments and preparing detailed lab reports as part of the engineering chemistry course. Students were provided with a model undergraduate engineering lab report which conformed to the report structure required by their content course instructor, but its subject matter, fluid dynamics, was not directly related to the labs that students were performing. The engineering instructor gave a brief talk introducing the basic concepts and terms necessary to understand the content of this model report, and students were then asked to read it before their next language class. During that class, the English instructor helped students identify the communicative purposes of each report section; notice specific language features that the report author had used in each section; and make connections between communicative purpose (e.g. to discuss a discrepancy between experimental values and literature values) and language features (e.g. the use of passive voice and 'hedging' modal verb phrases such as in 'may have been caused by'). Students were then required, over a series of three classes, to produce three small assignments related 
to the lab report genre: an abstract for the model report (whose original abstract had been excised before the report was given to students); a results-style description of the data in one of the figures from the report's appendix; and a discussion-like explanation of this data. The language instructor provided students with feedback on all three assignments, pointing out inaccuracies in language form but, more importantly, drawing the student writers' attention to instances in which language choices were inappropriate to a particular communicative purpose within the lab report genre.

In the second term, students were asked to submit their own lab reports on the determination of the molar volume of ideal gases to the language instructor. These reports had already been evaluated for their technical accuracy and merit as part of the engineering course. Teaching assistants in engineering courses are able to provide feedback on the technical content of lab reports, but are seldom in a position to provide comprehensive feedback on language issues, and it was thought that students would therefore benefit from additional, language-focused feedback on an actual course lab report. In order to understand the technical content of the lab well enough to evaluate how well student reports communicated their intended meanings, the language instructor performed the lab himself and wrote up his own report, which he submitted and received detailed feedback from the engineering instructor. The language instructor then read the student reports, highlighting problematic language areas and asking students to revise their reports on the basis of this language feedback. The revised reports were assessed as one of the major assignments in the language course.

\subsection{Listening Comprehension}

A second activity, centered on a podcast related to the use of redox reactions for energy generation, promoted the development of listening comprehension skills. Scheduled to coincide with the engineering instructor's lectures on redox reactions, this activity had students listen to a 10-minute excerpt from the CBC radio science show Quirks and Quarks in which the host interviewed a mechanical engineering researcher about his work on recyclable metal fuels as a possible alternative to fossil fuels. Before listening to the podcast, students acquainted themselves with its subject matter and language by reading through the abstract from the journal article in which the researcher originally published the work, and by going through a list of definitions of the more difficult technical terms that they would encounter while listening. The engineering instructor also gave a brief introduction to the podcast, previewing the technical chemistry concepts that would be mentioned and indicating how the researcher's recyclable metal fuels project related to the general principles of redox reactions that they had studied in class. Students were given a worksheet with questions to answer as they listened to the recording. They were allowed to listen to the podcast twice and after each listening session, in order to practice their speaking skills, they were permitted to discuss their answers with classmates. At the end of class, they submitted their completed worksheets for assessment as a quiz.

\section{PROGRAM OUTCOMES AND ANALYSIS}

\subsection{Student Performance}

At the time of writing Vantage students are in their final summer term, and full data on their overall performance throughout the program is not yet available. The observations described here are therefore limited to the courses covered in this paper. Based on the results currently available, however, Vantage students are performing as well or better than their counterparts in the direct-entry engineering courses, in terms of course averages. In terms of language and communication skills, a marked improvement was observed in the lab reports produced in the engineering courses, not only in terms of the quality of language, but also in the organization of the reports, and in the depth of analysis, likely the result of language-based activities focusing on individual report sections in turn.

\subsection{Student Feedback}

Feedback was collected at the end of each of the two completed terms through surveys administered by VC asking students what they thought of the integrated language approach, what type of activities they found useful, and what they think should be improved in subsequent years.

Overall the feedback was very positive, with most students indicating that they appreciated the opportunity to practice their communication skills by working on discipline-relevant tasks, and several students indicated that they were able to directly apply lessons and skills acquired during language classes to their lab reports and assignments in technical courses, and that their marks increased as a result of this. They also appreciated the opportunity to practice their speaking and listening skills on material directly related to the engineering courses they were taking, and that this helped them follow and understand lectures, which increased their level of participation and interest.

In terms of improvements or suggested changes, students indicated that they found the greatest value in the activities related to writing and formatting lab reports and giving oral presentations, and asked that the course focus 
more on these practical aspects, and less on grammatical theory and technical vocabulary, which they felt they could acquire as required. Many also voiced a desire for more group work to be implemented in the language courses.

\subsection{Challenges Encountered and Improvements to the Program}

Although the main objectives of the integrated approach were met, and overall student feedback was positive, two interrelated challenges were encountered with this program, namely the low level of engagement of some students, and a tendency among students to revert to their native language-rather than persevering in English — as a learning 'survival strategy'.

In terms of student engagement, it should be noted that although the overall feedback from students was quite positive, some students simply did not "buy-in" to the objectives of the instructional approach, and did not see the relevance of the language component of the Vantage program, which was not seen as important or relevant to their engineering studies. This was evidenced by a discrepancy, between the technical and language courses, in the quality of their work, the level of effort put forth, and the consistency of their class attendance. These students, based on survey results but also on informal conversations, only put in the minimum effort required to pass the language courses. A correlation between engagement and active participation in the language courses and performance in the engineering exams and lab reports-and more anecdotally with improvements in spoken language skills during interactions with the instructors from both courses-was observed. For the next year of the program, changes will be made to the content of the language course, putting more emphasis on work related to lab reports and technical oral presentations, and a greater, more direct effort will be made to persuade students of the importance of the language training for their studies and the benefits active participation in these courses can bring.

The second challenge, related to some extent to the first, is the reluctance of Vantage students to practice their English skills outside of directly supervised language training activities and lectures. There was an observed tendency for students to revert to their native tongues as soon as that supervision or evaluation was over, which is a well-documented challenge in multi-lingual learning environments [4]. Most of the students have the primary objective of obtaining an engineering degree at UBC, with the language training requirements of the Vantage program being a means to that end. Many of these students have therefore demonstrated unexpected levels of resourcefulness and expended great efforts in trying to circumvent the language components of the program, dismissing them as irrelevant to their technical training, which itself is heavily based on mathematics, which is already familiar to them. In the more extreme cases, these students do not do any of the assigned course readings, preferring to research course topics in resources written in their native language; do not consult course instructors or TAs; and translate all assignment questions prior to solving them, all of which directly impedes the development of their English communication skills. As a way to encourage students to work through-rather than try to 'get around' - the challenge of improving their English, next year short periodic reading comprehension or oral quizzes on assigned reading material will be given.

\section{CONCLUSIONS AND NEXT STEPS}

At the time of writing students are completing their third and final term of the pilot year of the Vantage APSC program. A comprehensive data set on the student experience, learning outcome assessment and student performance as they transition to their second year and progress through their studies is currently being collected, and a broader assessment of the effectiveness of the VC approach will be available in the near future. Based on preliminary data, however, although there are opportunities for improvement, the Vantage approach to engineering education has proven effective in improving student communication skills and disciplinary outcomes. The type of collaboration described adds value to academic programs, and certainly provides an interesting learning experience for students and instructors alike.

\section{Acknowledgements}

Thanks are extended to Dr. Joanne Fox, Principal and Academic Director of Vantage College, and Dr. Sandra Zappa-Hollman, Director of the Academic English Program at Vantage College, for their feedback on this paper and for sharing the results of student surveys.

\section{References}

[1] Ian Bruce. Theory and Concepts of English for Academic Purposes. New York: Palgrave Macmilland, 2011, 227 pp.

[2] Do Coyle, Philip Hood, and David Marsh. Content and language integrated learning. Cambridge: Cambridge University Press, 2010, 173 pp.

[3] Michael Halliday. An introduction to functional grammar. London: E. Arnold, 1994 (2nd ed.), 689 pp.

[4] Seyyed Hatam Tamimi Sa'd and Zohre Qadermazi. "L1 Use in EFL Classes with English-only Policy: Insights from Triangulated Data.” CEPS J., vol 5, no. 2, pp. 159-175. 